\title{
Electronics-Based Calculus: A Transposition Pilot Study
}

\author{
Sergio Camacho-Leon, Ph.D. ${ }^{1}$, and Jorge Quishpe-Armas, B.Sc. ${ }^{1}$ \\ ${ }^{1}$ Tecnologico de Monterrey, Mexico, sergio.camacho@itesm.mx, jaquishpe@espe.edu.ec
}

\begin{abstract}
The present paper describes the design, implementation and impact assessment of challenging and interactive learning experiences about the foundations of Calculus from the perspective of electronic circuits. Such activities were designed for undergraduate students of the areas related to Information Technology and Electronics and aim to explore context-rich problems as a teaching strategy for stimulating critical thinking, collaborative work and the use of new information technologies. The effectiveness and educational assessment of the developed activities are examined using the normalized gain metric from a diagnostic and final test, as well as an opinion survey; both applied during the fall 2014 semester to volunteer students enrolled in various academic programs of the School of Engineering and Information Technology at the Tecnologico de Monterrey, Campus Monterrey. Preliminary results are analyzed by academic program, advancement in the curriculum and methodology used; with the intention to draw recommendations for the eventual implementation of these activities in a college calculus course.
\end{abstract}

Keywords- Mathematics, Electronics, Information Technology, Flexible Learning, Critical Thinking.

Digital Object Identifier (DOI): http://dx.doi.org/10.18687/LACCEI2015.1.1.270

ISBN: 13 978-0-9822896-8-6

ISSN: $2414-6668$

13 ${ }^{\text {th }}$ LACCEI Annual International Conference: “Engineering Education Facing the Grand Challenges, What Are We Doing?” July 29-31, 2015, Santo Domingo, Dominican Republic

DOI: http://dx.doi.org/10.18687/LACCEI2015.1.1.270 


\title{
Electronics-based Calculus: A transposition pilot study
}

\author{
Sergio Camacho-Leon, Ph.D. ${ }^{1^{*}}$, and Jorge Quishpe-Armas, B.Sc. ${ }^{2}$ \\ Tecnologico de Monterrey, Mexico, ${ }^{1}$ sergio.camacho@itesm.mx, ${ }^{2}$ jaquishpe@espe.edu.ec
}

\begin{abstract}
The present paper describes the design, implementation and impact assessment of challenging and interactive learning experiences about the foundations of Calculus from the perspective of electronic circuits. Such activities were designed for undergraduate students of the areas related to Information Technology and Electronics and aim to explore context-rich problems as a teaching strategy for stimulating critical thinking, collaborative work and the use of new information technologies. The effectiveness and educational assessment of the developed activities are examined using the normalized gain metric from a diagnostic and final test, as well as an opinion survey; both applied during the fall 2014 semester to volunteer students enrolled in various academic programs of the School of Engineering and Information Technology at the Tecnologico de Monterrey, Campus Monterrey. Preliminary results are analyzed by academic program, advancement in the curriculum and methodology used; with the intention to draw recommendations for the eventual implementation of these activities in a college calculus course.

Keywords-- Mathematics, Electronics, Information Technology, Flexible Learning, Critical Thinking.
\end{abstract}

\section{INTRODUCTION}

The teaching of mathematics is an important goal to educate citizens with critical thinking, i.e. with the adequate skills to identify and solve problems in any context and to express, test, revise or even reject their own ways of thinking [1]. However, it is often difficult for engineering students to apply what they have learned in previous math courses, leading to a mistaken belief that mathematics is not relevant for them. For example, Gainsburg noted that there is a difference between mathematics used by professionals and mathematics encountered in schools and universities [2].

In order to overcome this mistaken belief, the development of activities that enable students to recognize the importance of mathematics in everyday situations is required. Therefore, the proposed approach builds on the same inductive philosophy of inquiry-based learning and problem-based learning [3] to study a new context for teaching calculus to undergraduate students of the areas related to Information Technology and Electronics, which aims to explore the foundations of calculus from the perspective of electrical circuits and/or analog electronics as a teaching strategy to stimulate critical thinking, collaborative work and the use of new information technologies.

\section{DEVELOPMENT}

In an attempt to evaluate the teaching effectiveness of this transpositional approach, a pilot study was designed based on the following contents of a differential calculus course at the undergraduate level [4]:

- Definition of a function and its several representations.

- Continuity of a function at a point $(f: \mathbb{R} \rightarrow \mathbb{R})$.

- Lateral continuity $(f: \mathbb{R} \rightarrow \mathbb{R})$.

- $\quad$ Functions defined by intervals $(f: \mathbb{R} \rightarrow \mathbb{R})$.

- Continuity on intervals $(f: \mathbb{R} \rightarrow \mathbb{R})$.

The study involves the design, implementation and impact assessment of a 1.5 hours learning experience, comprising several strategies that complement each other and are described below:

\section{A. Diagnostic Test}

Previous to the experience, all students took an individual test about the theoretical foundations of the topics of study. The diagnostic test consisted of five multiple choice questions with increasing difficulty level, which were applied through the online Learning Management System Blackboard Learn (Release 9.1) [5]. This allowed to offer the student a direct, specific and immediate feedback on their previous knowledge on the topics.

\section{B. Tutorial}

At the beginning of the experience, $50 \%$ of students collaboratively analyzed by theory, simulation and experimentation the behavior of an electronic circuit that was specifically designed to relate the topics of study to a realworld problem, as shown in Fig. 1. The other $50 \%$ of students only performed a theoretical analysis of the circuit.

\section{Final Test}

To conclude the experience, all students took an individual test comprising ten multiple choice questions with increasing difficulty level about the theoretical foundations of the topics of study in the context of electrical variables, as shown in Fig. 2.

\footnotetext{
* Corresponding author
}

$13^{\text {th }}$ LACCEI Annual International Conference: “Engineering Education Facing the Grand Challenges, What Are We Doing?” 

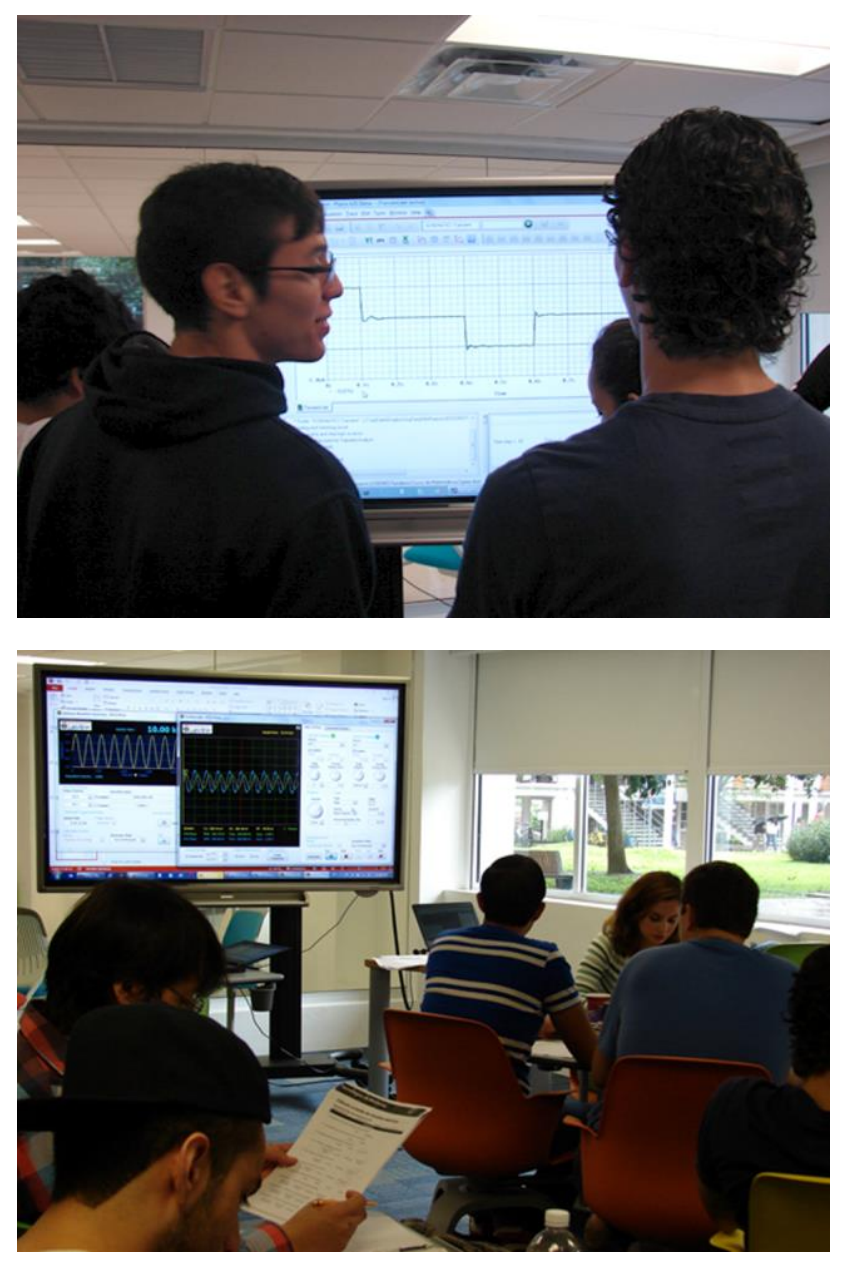

Fig. 1 Students taking the tutorial: at the simulation station (top) and at the experimental station (bottom).

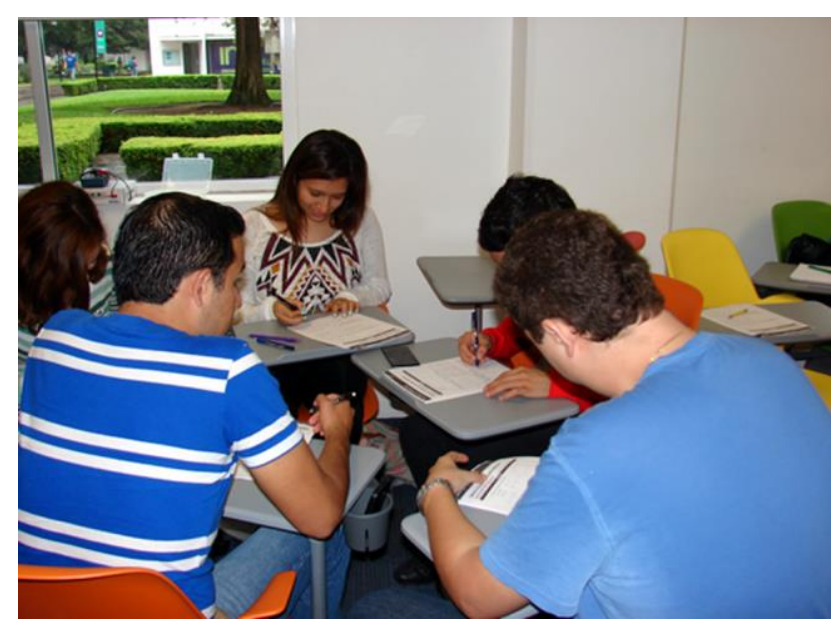

Fig. 2 Students taking the final test.

\section{Opinion inquiry}

After the experience, all students answered a survey with a Likert scale of 1-5 (where 1 indicates complete agreement and 5 indicates complete disagreement) on the following aspects:

E1) This activity allowed me to understand the relationship between the topics of study and reality.

E2) This activity innovated my learning experience.

E3) This activity included technological resources that added value to my learning experience.

E4) This activity demanded my best, maintaining a high intellectual challenge for the benefit of my learning.

E5) In general, I believe that this experience was excellent.

The overall experience was applied twice during the Fall 2014 semester with a total participation of 48 volunteer students enrolled in various academic programs of the School of Engineering and Information Technology at the Tecnologico de Monterrey, Campus Monterrey; of which $21 \%$ of them is enrolled in an international curriculum modality and $\sim 46 \%$ of them have more than a year after taking the differential calculus course.

\section{RESULTS}

The results obtained in this pilot study are presented in Table I, where the normalized gain is given by

$$
g=\left(T_{f}-T_{d}\right) /\left(100-T_{d}\right),
$$

where $T_{f}$ and $T_{d}$ are the average results of the final and diagnostic test, respectively [6].

As shown in Table I, students from the international modality obtained in average the highest normalized gain $(g=$ 0.52 ). In addition, they all are in complete agreement that this experience allowed them to understand the relationship between the topics of study and reality $(\mathrm{E} 1=1.00)$ as well as that it demanded their best, maintaining a high intellectual challenge for the benefit of their learning $(\mathrm{E} 3=1.00)$.

Moreover, students who performed analysis by theory, simulation and experimentation have in average a better opinion in all aspects $(E i)$ than those who only performed a theoretical analysis, even when there is no significant difference in their normalized gains ( $g=0.38$ vs $g=0.37$ ).

It is also noteworthy that students who have more than a year after taking the differential calculus course averaged a higher normalized gain than those who have less than a year ( $g$ $=0.41$ vs $g=0.33$ ), even when the average opinion of the latter is better in all aspects $(\mathrm{E} i)$ than the former.

13 $^{\text {th }}$ LACCEI Annual International Conference: "Engineering Education Facing the Grand Challenges, What Are We Doing?" 
TABLE I.

\begin{tabular}{|c|c|c|c|c|c|c|c|c|c|c|}
\hline & \multicolumn{2}{|c|}{ Diagnostic Test } & \multicolumn{2}{|c|}{ Final Test } & \multirow{2}{*}{$\begin{array}{l}\text { Normalized gain } \\
\qquad(g)\end{array}$} & \multicolumn{5}{|c|}{ Opinion poll } \\
\hline & $\begin{array}{c}\text { Average } \\
(\%)\end{array}$ & $\begin{array}{c}\text { Standard } \\
\text { deviation (\%) }\end{array}$ & $\begin{array}{c}\text { Average } \\
(\%)\end{array}$ & $\begin{array}{c}\text { Standard } \\
\text { deviation }(\%)\end{array}$ & & E1 & E2 & E3 & $\mathrm{E} 4$ & E5 \\
\hline Students... & 55 & 22 & 72 & 17 & 0.38 & 1.67 & 1.83 & 1.58 & 1.96 & 1.58 \\
\hline $\begin{array}{c}\text { in an international } \\
\text { curriculum } \\
\text { modality } \\
10\end{array}$ & 71 & 4 & 86 & 10 & 0.52 & 1.00 & 1.60 & 1.00 & 1.80 & 1.40 \\
\hline $\begin{array}{c}\text { who have more } \\
\text { than a year after } \\
\text { taking the } \\
\text { differential calculus } \\
\text { course } \\
22 \\
\end{array}$ & 42 & 26 & 66 & 15 & 0.41 & 2.18 & 2.18 & 2.18 & 2.45 & 1.82 \\
\hline $\begin{array}{c}\text { who have less than } \\
\text { a year after taking } \\
\text { the differential } \\
\text { calculus course } \\
26\end{array}$ & 65 & 12 & 77 & 17 & 0.33 & 1.23 & 1.54 & 1.08 & 1.54 & 1.38 \\
\hline $\begin{array}{l}\text { who performed } \\
\text { analysis by theory, } \\
\text { simulation and } \\
\text { experimentation } \\
24\end{array}$ & 63 & 16 & 77 & 19 & 0.38 & 1.58 & 1.75 & 1.33 & 1.75 & 1.33 \\
\hline $\begin{array}{c}\text { who only } \\
\text { performed a } \\
\text { theoretical analysis } \\
24\end{array}$ & 47 & 26 & 67 & 12 & 0.37 & 1.75 & 1.92 & 1.83 & 2.17 & 1.83 \\
\hline
\end{tabular}

\section{CONCLUSION}

In this study we have provided insights into how students deal with calculus problem solving. The effectiveness and educational assessment of the proposed approach have been analyzed using the normalized gain metric and an opinion survey, with a special emphasis on the major challenges that students experienced by academic program, advancement in the curriculum and methodology used.

The study supports the conclusion that a course in problem solving - or similar teaching - is important in the curriculum. We can add that this transposition approach has been exceptionally well received by students from international modalities and at early levels in their education, which generally acknowledge that the use of technological resources add value to their learning experience and give them a significant increase in their analytical skills.

On a more general level, we see cognitive apprenticeship as a promising framework for teaching and learning in higher education [7]. A fundamental component of cognitive apprenticeship is that teachers model and verbalize the cognitive processes that experts engage in when they solve problems. This act of "making thinking visible" [8] is preferably carried out in collaboration with the students and by using real-life examples. We believe that this approach to teaching also has the potential to enhance students learning at higher levels.

\section{ACKNOWLEDGMENT}

The authors acknowledge support from the Centro de Desarrollo Docente e Innovación Educativa (CEDDIE), as well as the Department of Electrical and Computer Engineering and the Department of Mathematics of the School of Engineering and Information Technology at Tecnologico de Monterrey, Campus Monterrey.

\section{REFERENCES}

[1] R. Rodríguez, "Innovation in the Teaching of Mathematics for Engineers through Modeling and Technology: a Mexican Experience", Proceedings American Society for Engineering Education International Forum, USA, 8339, 2013.

[2] J. Gainsburg, "The mathematical modelling of structural engineers," Mathematical Thinking and Learning, vol. 8, no.1, pp. 3-36, 2006.

[3] M. J. Prince, R. M. Felder, "Inductive teaching and learning methods: Definitions, comparisons and research bases," Journal of Engineering Education, vol. 95, no. 2, pp. 123-138, 2006.

[4] Mathematics I course program, Tecnologico de Monterrey, Mexico, 2014, http://serviciosva.itesm.mx/PlanesEstudio/Consultas/Materias/ConsultaM aterias.aspx?ClaveMateria=MA1015

[5] Blackboard Learn (Release 9.1), US, 2014, http://www.blackboard.com/Platforms/Learn/Overview.aspx.

[6] Hake, R. (1998). Interactive engagement vs. Traditional methods: a sixthousand student survey of mechanics test data for introductory physics. American Journal of Physics, 66 (1) 64-74.

[7] J. S. Brown, A. Collins, P. Duguid, "Situated cognition and the culture of learning,” Educational Researcher, vol. 18, no. 1, pp. 32-42, 1989.

[8] A. Collins, J. Brown, A. Holum, "Cognitive apprenticeship: Making thinking visible,” American Educator, vol. 6, no. 11, pp. 38-46, 1991.

$1^{\text {th }}$ LACCEI Annual International Conference: "Engineering Education Facing the Grand Challenges, What Are We Doing?" July 29-31, 2015, Santo Domingo, Dominican Republic 